\title{
Análise dos Impactos da Competição pelo Uso do Solo no Estado de Goiás Durante o Período 2000 a 2009 Provenientes da Expansão do Complexo Sucroalcooleiro
}

\author{
Klaus de Oliveira Abdala*, Francis Lee Ribeiro ${ }^{\dagger}$
}

Conteúdo: 1. Introdução; 2. Metodologia; 3. Resultados e Discussão; 4. Conclusões.

O objetivo deste artigo é analisar a especialização dos municípios do estado de Goiás em cana-de-açúcar, como resultado da competição pelo uso do solo, e os impactos decorrentes deste processo na substituição de culturas, no uso de remanescentes florestais e no uso consuntivo de água pela cultura da cana. Os resultados sugerem que a expansão da cana-de-açúcar especializa municípios, nos quais substitui preferencialmente as culturas temporárias e induz ao deslocamento de culturas, pressionando remanescentes florestais. Além disso, parte dessa expansão localiza-se em áreas de médio a elevado risco de deficiência hídrica para a cultura da cana.

This article aims to analyze the sugarcane specialization in Goiás State, at the municipal level, as a result of competition for land use and the impacts of this process on: substitution of crops, in the use of forest remnants and in the consumptive use of water by sugarcane. The results suggest that the expansion of sugar cane promotes local specialization, where, preferentially, replaces temporary crops and induces the displacement of the other crops, endangering the forest fragments. In addition, part of the expansion is located in areas of moderate to high risk of drought for sugar cane cultivation.

Palavras-chave: Tamanho e distribuição regional de atividade econômica; Conservação dos recursos naturais e renováveis; Florestas; Água.

Códigos JEL: $\quad$ R12; Q2; Q23; Q25.

\footnotetext{
*Doutorando Programa Multidisciplinar de Doutorado em Ciências Ambientais - CIAMB - Universidade Federal de Goiás - UFG E-mail: agroklaus@gmail.com

${ }^{\dagger}$ EA - Setor de Desenvolvimento Rural - Universidade Federal de Goiás - UFG E-mail: francisleerib@gmail.com
} 


\section{INTRODUÇÃO}

O Brasil é o maior produtor mundial de cana-de-açúcar, seguido pela Índia, Tailândia e Austrália. Em média, nas últimas safras brasileiras, $52 \%$ da produção nacional destinaram-se a produção de etanol (anidro e hidratado) e $48 \%$ a de açúcar. A cultura espalha-se pelo Centro-Sul e pelo Norte-Nordeste, ocupando cerca de 7 milhões de hectares ou aproximadamente $2 \%$ de toda a terra arável do país.

Os estados mais representativos das regiões brasileiras são: Paraná, na região Sul; São Paulo, na região Sudeste, Alagoas, no Nordeste. Goiás destaca-se na região Centro-Oeste ocupando a quarta posição no país, após São Paulo, Paraná e Minas Gerais (UNICA, 2010).

A introdução do cultivo da cana-de-açúcar em Goiás ocorreu juntamente com a expansão de fronteiras no Estado, no início do século XIX, com a montagem de pequenos engenhos de fabricação de rapadura e cachaça artesanais. Segundo o Ministério das Relações Exteriores (MRE, 2010), um dos engenhos mais antigos é o São Joaquim, em Pirenópolis, edificado em 1805 para a produção de açúcar e aguardente. A cultura da cana-de-açúcar disseminou-se juntamente com a produção pecuária, uma vez que os engenhos eram movidos a energia animal.

A maior expansão da cultura da cana no Brasil ocorreu no período de implantação do Programa Nacional do Álcool (Proálcool) em 1975. A $1^{\text {a }}$ fase do Programa (1974-1979) foi marcada pela produção de álcool anidro, fabricado em destilarias anexas às usinas de açúcar. $\mathrm{O}$ álcool anidro foi utilizado para misturar-se a gasolina e, com isso, possibilitar a economia de divisas derivadas da importação de petróleo. Em Goiás, os reflexos dessa fase são observados somente nos municípios de Santa Helena, que apresentou um aumento de 150\% em área de cana-de-açúcar colhida, passando de 2.200 ha, em 1974, para 4.600 ha, em 1979, e em Goianésia, que apresentou um aumento de aproximadamente 100\% na área colhida, passando de 2.900 ha, em 1974, para 5.900 ha, em 1979 (IPEADATA, 2010).

A $2^{\mathrm{a}}$ fase (1979-1986) é iniciada com o $2^{\circ}$ choque do petróleo o qual implicou em vultuosos aumentos de seu preço. É caracterizada pela produção de álcool hidratado para atender ao consumo em ascensão dos veículos movidos exclusivamente a álcool. Nessa fase há uma grande ampliação das destilarias anexas às usinas de açúcar e o surgimento de destilarias autônomas e, consequentemente, um grande crescimento do volume produzido de álcool, que passou de 3.396,4 mil $\mathrm{m}^{3}$ em 1979, para 10.539,3 mil $m^{3}$, em 1986. Esse período consolidou a produção sucroalcooleira em Goiás, ao longo do eixo Norte-Sul, induzida pelas principais vias de escoamento do Estado (Miziara e Ferreira, 2008).

O preço do petróleo começou a cair abruptamente, baixando de US\$27,00/barril, em 1985, para menos de US\$ 14,00/barril, a partir de 1986, impossibilitando o governo de manter o estímulo de preços ao álcool. O consumo de álcool hidratado continuou crescendo. Entre 1989 e 1990, porém, houve uma crise de abastecimento que levou a população a perder a confiança nesse combustível e, consequentemente, no carro a álcool, cujas vendas caíram para 11,55\%, em 1990, contra 52,5\% no ano anterior PNA (2006).

Segundo Michellon et alii (2008), em meados dos anos 1990, o governo promoveu a desregulamentação do setor liberando os preços para a livre concorrência. O setor sucroalcooleiro procurou se organizar, dando origem a formação de entidades como ÚNICA e SUCROÁLCOOL e buscar formas para dar novo fôlego ao programa e ao setor. Assim, esse período (1986-1995) pode ser evidenciado como a $3^{\text {a }}$ fase do Proálcool. Em Goiás ocorreu uma diminuição da área colhida da cultura de cana-de-açúcar, que passou de 110.430 ha, em 1986, para 104.498 ha em 1997.

Estimulados pela expectativa de aumento de demanda interna por etanol, devido à popularização dos carros bicombustível, e demanda externa, em função do Protocolo de Kyoto e, também devido a elevação dos preços internacionais do açúcar, agentes de decisão administrativa no setor sucroalcooleiro iniciaram, à partir de 2003, uma expansão com precedentes análogos às históricas marchas pioneiras de ocupação de fronteiras no Brasil. Esse processo de expansão evidenciou a $4^{\mathrm{a}}$ fase de expansão ao setor sucroalcooleiro (2003 - atual) no Brasil e, particularmente, no estado de Goiás. 
Segundo o MAPA (2010), Goiás apresentou a segunda maior quantidade de usinas sucroalcooleiras cadastradas $^{1}$ nos últimos seis anos, ficando atrás apenas do estado de São Paulo. De 2004 a 2010, o Estado apresentou cadastro para 71 novas usinas, enquanto São Paulo apresentou 196 novos cadastros e, em terceiro lugar, Minas Gerais apresentou 37 novos cadastros.

A literatura relata uma série de impactos ambientais relacionados à cana-de-açúcar de açúcar, tais como a queimada da cana e a geração de resíduos como a vinhaça e a torta de filtro entretanto, segundo a EMBRAPA-CNPM (2011), a evolução tecnológica e institucional do setor sucroalcooleiro vem ocorrendo continuamente no sentido de mitigar ou eliminar tais impactos. Apesar disso, ainda persistem os temores de impactos relacionados ao desflorestamento, induzido pela expansão da produção de cana-de-açúcar, e ao uso consuntivo de água, sobretudo em regiões especializadas na cultura.

Segundo Abdala e Castro (2010), as regiões do bioma Cerrado constituem forte atrativo para novos empreendimentos sucroalcooleiros, sobretudo devido as suas características edafoclimáticas. 0 potencial agrícola dos solos de Cerrado no Centro-Oeste brasileiro é, em termos de classificação (umidade, fertilidade e textura), em sua grande maioria, o mesmo encontrado no oeste do Estado de São Paulo, região na qual se considera a existência dos melhores solos para plantio desta cultura. Goiás apresenta ainda climas de médio à alto potencial para a produção de cana-de-açúcar, com elevado potencial para irrigação da cultura.

Apesar de estudos, tais como os apresentados pelo Plano Nacional de Agroenergia (PNA, 2006) e pela Universidade de Campinas (UNICAMP, 2005) sugerirem a necessidade de desconcentração espacial da produção sucroalcooleira e de sua expansão em substituição às áreas de pastagens de baixa produtividade, esta expansão, conforme os princípios de maior lucratividade induzida por imperativos capitalistas, parece ocupar inicialmente as áreas de maior potencial produtivo, sendo direcionada para solos de uso agrícola e sugerindo concentração espacial.

De fato, Castro et alii (2007), analisando a distribuição das usinas sucroalcooleiras instaladas e em instalação no estado de Goiás, concluíram que tal distribuição define, no Estado, uma espécie de zoneamento induzido pelo setor produtivo, relacionado aos principais eixos rodoviários que servem o Centro-Sul Goiano. Analisando os declives dos terrenos, os solos e seus potenciais para o plantio, excluídas as Unidades de Conservação e as Áreas Prioritárias para Conservação, concluíram, também, que mais da metade do território goiano (cerca de 60\%) contém solos com elevada a moderada aptidão agrícola para a cultura da cana e que aproximadamente $60 \%$ das usinas instaladas estavam em áreas de uso agrícola.

Para atender a essa perspectiva de demanda sucroalcooleira em Goiás, estimou-se a necessidade de incorporação de cerca de 3 milhões de hectares de novas áreas. Entretanto, segundo Vieira Jr. et alii (2008), esse não é o maior problema uma vez que a cana-de-açúcar ocupa menos de $10 \%$ da área agrícola atual no Estado e ainda, existe uma ampla disponibilidade de terras agricultáveis. ${ }^{2}$ Os autores acreditam que a expansão de área com cana-de-açúcar poderá resultar em deslocamento de culturas dentro do estado de Goiás para áreas de menor aptidão agropecuária, concentrando espacialmente a produção de cana e acentuando os desflorestamentos decorrentes dessa dinâmica.

Diante disso, Abdala e Castro (2010), analisando a dinâmica de uso do solo da expansão sucroalcooleira na microrregião Meia Ponte, no estado de Goiás, concluíram que a expansão da lavoura sucroalcooleira se concentrava na região sudoeste desta microrregião, com maior concentração das culturas temporárias, solos mais profundos (Latossolos) e planos, promovendo deslocamento das culturas temporárias, para o norte da microrregião, substituindo áreas de pastagens.

\footnotetext{
${ }^{1} \mathrm{O}$ Ministério da Agricultura mobiliza as áreas de sua estrutura na organização do banco de dados, á partir destes cadastros, para identificação e localização dos estabelecimentos legalmente constituídos no País, assim, esses cadastros controlam a produção de setores estratégicos, como o da agroenergia (MAPA, 2010).

${ }^{2}$ De acordo com os dados do IBGE-PAM (2010), a área agropecuária utilizada em Goiás, no ano de 2009, foi de 20.159.854 ha nesse ano, a cana de açúcar ocupou uma área de 515.608 ha, o que representa 2,6\% da área agropecuária em 2009.
} 
Ainda segundo Abdala e Castro (2010), a análise específica dessa dinâmica nos municípios do estado de Goiás, poderá aprofundar os resultados obtidos em seu estudo, agregando informações que permitam analisar impactos na sustentabilidade do desenvolvimento desses locais, uma vez que em Goiás, excetuadas as áreas de preservação permanente e reservas legais, ainda existem remanescentes de Cerrado com possibilidade de desmatamento.

Com relação ao uso consuntivo da água, Silva et alii (2008), analisaram o balanço hídrico para a cultura da cana-de-açúcar no estado de Goiás e, segundo eles, com a expansão deste cultivo no Estado haverá necessidade de irrigação de salvamento ${ }^{3}$ com lâminas de água entre $80 \mathrm{~mm}$ e $120 \mathrm{~mm}$, em algumas de suas regiões. Se essas aplicações de água não forem bem planejadas, podem gerar consequências irreversíveis sobre a biodiversidade e conflitos pelo o uso dos recursos hídricos.

Silva et alii (2008), concluíram que as áreas com maior demanda de água para irrigação da cana-deaçúcar no estado de Goiás (porção noroeste do estado) são as que possuem as menores disponibilidades hídricas nos rios, assim, devem receber atenção especial quanto à introdução dessa cultura. A região sudoeste do Estado, de forma geral, não apresenta restrições hídricas com relação ao cultivo de canade-açúcar e no restante do Estado, há condições hídricas para o cultivo de cana-de-açúcar, contudo, a relação entre a oferta e a demanda hídrica para essa prática deve ser sempre avaliada com muita atenção.

A partir de 2004, Goiás vem sendo marcado por movimentos de expansão de fronteiras com elevada competição pelo uso do solo. Segundo dados do IBGE-PAM (2010), é possível identificar a presença de quatro principais complexos agroindustriais: ${ }^{4}$ bovinos, soja e milho e cana-de-açúcar, responsáveis pelo uso e ocupação de aproximadamente $97 \%$ dos solos. Tais complexos estabelecem uma situação de competição por terras agricultáveis e por recursos naturais, sendo responsáveis por diferentes externalidades em seus processos.

Assim, este artigo tem o objetivo de analisar a especialização sucroalcooleira no estado de Goiás, como resultado da competição pelo uso do solo a nível municipal e os impactos decorrentes deste processo na substituição de culturas, no uso de remanescentes florestais e no uso consuntivo de água pela cultura da cana.

A identificação da especialização local para a cultura de cana-de-açúcar e das culturas deslocadas pelo processo de especialização, fornece informações para outros estudos que pretendam analisar a sustentabilidade desses municípios, constituindo, portanto, um referencial para políticas públicas de desenvolvimento local e estadual. Além disso, a análise do uso consuntivo de água fornecerá subsídios para a gestão de recursos hídricos pelo setor público, no sentindo de antecipar impactos decorrentes da disputa por esses recursos.

\subsection{Especificamente pretende-se:}

1. Identificar os municípios especializados na produção de cana-de-açúcar no estado de Goiás;

2. Analisar as fontes de expansão da área de produção da cana-de-açúcar nos municípios;

3. Analisar os impactos decorrentes da especialização produtiva dos municípios no uso consuntivo de água e no desflorestamento de remanescentes florestais;

4. Analisar a expansão da produção de cana-de-açúcar no estado de Goiás, no período de 2000 a 2009, identificando a vantagem econômica deste complexo em relação aos demais complexos substituídos.

\footnotetext{
${ }^{3}$ Salvamento se refere à prática de irrigação da cultura da cana quando plantada ou colhida no início da estação seca, com a finalidade de garantir sua rebrota (Silva et alii, 2008).

${ }^{4}$ Segundo Batalha (2001), o termo complexo agroindustrial refere-se ao conjunto de operações técnicas, relações comerciais e ações econômicas responsáveis pela geração de uma determinada matéria prima agroindustrial.
} 


\section{METODOLOGIA}

Para identificar os municípios especializados serão utilizados como referencial analítico o Quociente de Localização, Coeficiente de Especialização e o Índice de Theil.

Lopes (2001) analisa as principais medidas de localização e especialização utilizadas na literatura, segundo o autor é comum distinguirem-se as Medidas de Localização das Medidas de Especialização: as primeiras têm por objetivo comparar a expressão de uma determinada atividade econômica, em territórios distintos (seguem, portanto, uma perspectiva de abordagem setorial), as outras avaliar o grau de especialização de um território, em função de um conjunto de atividades.

\subsection{Variáveis utilizadas}

Para o cálculo do Quociente de Localização, Coeficiente de Especialização e do Índice de Theil, serão utilizadas as seguintes variáveis

$$
\begin{aligned}
& \text { QL - Quociente de localização; } \\
& \text { CE - Coeficiente de especialização; } \\
& \text { IT - Índice de Theil; } \\
& X_{r j} \text { - Área colhida da cultura } j \text { no município } r ; \\
& X_{r} \text { - Área colhida total das culturas consideradas, no município } r \text {; } \\
& X_{p j} \text { - Área colhida da cultura } j \text { no estado de Goiás; } \\
& X_{p} \text { - Área colhida total das culturas consideradas no estado de Goiás. }
\end{aligned}
$$

O Quociente de Localização é uma medida essencialmente voltada para avaliar o grau relativo de concentração de uma determinada atividade, apesar disso, a estrutura dos seus resultados permite fazer uma análise centrada numa região específica, para todos os setores de atividade em causa e, deste modo, tecer considerações sobre o grau de especialização/diversificação desse território, sendo obtido pela seguinte expressão:

$$
Q L=\frac{X_{r j} / X_{r}}{X_{p j} / X p}
$$

Na interpretação dos resultados, valores inferiores a 1 significam uma expressão da cultura $j$ no município $r$ inferior à expressão dessa cultura no estado de Goiás ; valores superiores a 1 significam uma expressão da cultura $j$ superior à verificada no estado de Goiás, ou seja, a região em questão é mais especializada na cultura $j$ do que o estado de Goiás.

Segundo Haddad (1989), no cálculo do Quociente de Localização é comparada a importância da atividade $j$ na região $r$, com a importância que essa mesma atividade tem numa região padrão $p$. A região padrão é a região (ou agregado de regiões) de referência, que pode ser o espaço composto pelo conjunto de regiões em análise ou outra região distinta, para a qual se assume existir uma distribuição setorial "ótima" da variável em análise.

O Coeficiente de Especialização é uma medida relativa que, ao contrário do Quociente de Localização, detém uma forte capacidade de síntese, nomeadamente quando se procuram obter respostas a questões do tipo "qual o grau de especialização de uma determinada região?"

Segundo Haddad (1989), o Coeficiente de Especialização regional produtiva compara a participação percentual da composição das atividades no local com a participação percentual da composição das atividades no Estado e constitui um índice de especialização produtiva, assim, o Coeficiente de Especialização mede o grau de concentração que uma região detém em relação aos setores da atividade econômica que nela estão implantadas, sendo obtido pela seguinte expressão: 


$$
C E=\frac{1}{2} \sum_{j=1}^{n}\left|\frac{X_{p j}}{X_{p}}-\frac{X_{r j}}{X_{r}}\right|
$$

Assim, um município com $C E=0$ significa que a composição de culturas agropecuárias deste é integralmente equivalente à estrutura apresentada pelo estado de Goiás; inversamente, quanto mais próximo de 1 for o $C E$, mais especializada é a estrutura agropecuária produtiva deste município relativamente à de Goiás.

Apesar da utilidade inegável do Quociente de Localização e do Coeficiente de Especialização, a análise dos resultados obtidos deve ser feita com precaução, uma vez que os resultados estão totalmente dependentes da distribuição setorial apresentada pela região padrão. Numa abordagem regional, quando se tecem considerações sobre a especialização de uma região num determinado ramo, deve-se ter presente que o que está na base para essa consideração é apenas um elevado nível de expressão de um ramo face à importância que este assume na região padrão.

Além disso, quando se considera como região padrão o agregado das regiões em análise é necessário ter atenção à dimensão de cada região (medida por meio da variável retida para análise): se existe uma região com uma importância muito superior as outras, esta região terá mais força na determinação da estrutura setorial da região padrão, e consequentemente, tenderá a surgir "apagada" em termos de especialização.

Os resultados podem, por vezes, estarem de tal forma dependentes da região padrão escolhida que a expressão real dos setores com coeficientes elevados, no contexto da própria região, podem não ter qualquer significado.

o Índice de Theil é um índice sintético que permite medir o grau de especialização de uma região. Ao contrário dos outros indicadores apresentados, este índice é um indicador bruto, que compara a expressão de uma atividade em relação ao conjunto de atividades da própria região eliminando-se, deste modo, a discussão inerente à definição de uma região de referência. Assim, o grau de especialização obtido através do Índice de Theil depende apenas da estrutura setorial da região em análise, sendo obtido pela expressão:

$$
I T=\sum_{j=1}^{n}\left|\frac{X_{r j}}{X_{r}} * \log \left(\frac{X_{r j}}{X_{r}}\right)\right|
$$

O conjunto de medidas apresentadas permite avaliar a estrutura produtiva de uma região e medir o grau de especialização que essa estrutura comporta. No entanto, essas medidas atuam de formas distintas: enquadrando a estrutura regional num outro contexto territorial, medindo assim o grau de especialização regional relativamente a uma região de referência (Quociente de Localização e Coeficiente de Especialização) ou, simplesmente através da estrutura especifica de uma região (Índice de Theil).

A utilização de uma, ou outra medida, não é consensual sendo certo que a escolha depende dos objetivos pretendidos, assim, uma análise que integre mais que uma medida será mais rica e conclusiva. Se, por um lado, através do Quociente de Localização se obtêm resultados mais desagregados, que permitem efetuar análises mais exaustivas, ambos, o Coeficiente de Especialização e o Índice de Theil, permitem classificar de forma imediata a posição das regiões.

A utilização das medidas relativas pode ser vantajosa em análises em que é necessária a contextualização das especificidades regionais em outros territórios. A utilização do Índice de Theil apenas para uma região diminui a possibilidade de interpretação dos resultados, sendo por isso vantajoso analisar os resultados deste índice comparativamente a outras regiões que apresentem um quadro de referência comum relevante (proximidade geográfica, estratégias de desenvolvimento similares, etc.).

Além dessas limitações, tais indicadores permitem apenas a análise estática, para um ano agrícola, não refletindo a evolução da dinâmica dos setores agropecuários. Portanto, optou-se por adotar também, o modelo "shift-share", ou modelo diferencial-estrutural. 
Vários trabalhos foram realizados utilizando a metodologia "shift-share" principalmente na análise do desenvolvimento agrícola: Curtis (1972); Patrick (1975); Zockun (1978); Igreja et alii (1983); Yokoyama (1992); Cardoso (1995); Moreira (1996); Alves (2000); Shikida e Alves (2001); Silva e Santos (2001); Figueiras (2002); Souza e Lima (2002); Almeida (2003); Igreja et alii (2006); Scheer (2008) e Paranaíba e Pires (2009). Tais trabalhos utilizam uma variação formal do método para identificação de fontes de crescimento, desempenho e indicadores de modernização agropecuária. A forma de decomposição de taxas diferenciais de crescimento é a mesma do método original, que utiliza as variáveis de geração de emprego para os setores em análise, porém as variações a serem medidas refletem a realidade da dinâmica agrícola. Estimam-se efeitos área, rendimento, localização e produtividade, dentre outros.

O modelo "shift-share" consiste, basicamente, na descrição do crescimento econômico de uma região em termos de sua estrutura produtiva. Sua aplicação no setor agropecuário procura explicar o comportamento da produção agrícola mediante a decomposição dos fatores responsáveis pela variação da produção. O crescimento das culturas é explicado por dois componentes: o estrutural, que está ligado à composição das atividades agropecuárias da região, e o diferencial, relacionado às vantagens locacionais comparativas em presença destas atividades.

Tal método tem como características não demandar muitas informações, ser aplicado para fins descritivos com informações cujo intervalo deve ser o maior possível e ser constituído por relações contábeis e definições, não apresentando hipóteses comportamentais para as variáveis (Haddad, 1989).

Considerando-se como setor dinâmico aquele que cresce a taxas maiores que a média, o método parte da constatação empírica de que há diferenciais setoriais e regionais nos ritmos de crescimento entre dois períodos de tempo. Tal diferença nos ritmos de crescimento pode ser atribuída a dois fatores:

i) a predominância de setores mais (menos) dinâmicos na composição produtiva da região; e

ii) uma maior (menor) participação na distribuição regional da variável básica, independentemente da ocorrência em setores mais (menos) dinâmicos.

Segundo Moreira (1996) o método utiliza três efeitos explicativos na variação da produção:

a) efeito área - EA;

b) efeito rendimento ou produtividade - ER;

c) efeito localização geográfica - EL.

O efeito área constitui um indicador de mudanças na produção provenientes de alterações na estrutura agrária, supondo que os demais efeitos permanecem constantes no decorrer do tempo. Dessa forma, um aumento na produção é atribuído à incorporação de novas áreas, indicando um uso extensivo do solo.

O efeito rendimento quantifica a variação na quantidade produzida decorrente da variação exclusivamente na produtividade, refletindo diferenciais tecnológicos nos fatores de produção.

Apesar de o progresso tecnológico ser considerado a partir da avaliação do ganho de produtividade total (Silva, 1984), a inexistência de dados de uso dos fatores de produção impossibilita essa quantificação, assim, à produtividade da terra, tomada como produtividade da cultura, normalmente tem sido usada como "proxy" das mudanças tecnológicas.

O efeito localização geográfica quantifica as variações na quantidade produzida provenientes das vantagens comparativas, ou seja, da mudança na localização das culturas entre as microrregiões estudadas, mantendo-se os demais componentes constantes.

Zockun (1978) apresenta que a área cultivada por determinada cultura, dentro do sistema de produção, pode ser modificada por dois fatores:

i) escala: variação da área total das culturas estudadas; 
ii) substituição: variação da participação de cada cultura dentro do sistema de produção.

Esse último fator, quando positivo, indica que no período analisado a cultura considerada se expandiu, ganhando área de outras culturas e aumentando sua participação. Quando for negativo, indica substituição por outra cultura dentro do sistema.

\subsection{Variáveis utilizadas}

\begin{tabular}{ll}
\hline$Q_{c t}$ & quantidade colhida da $c$-ésima cultura no estado de Goiás, no período $t ;$ \\
$A_{c m t}$ & área total colhida da $c$-ésima cultura, no $m$-ésimo município, no período $t ;$ \\
$A_{c t}$ & área total colhida da $c$-ésima cultura no estado de Goiás, no período $t ;$ \\
$A_{m t}$ & área total colhida das culturas no $m$-ésimo município do estado de Goiás, no período $t ;$ \\
$A_{t}$ & área total colhida das culturas no estado de Goiás, no período $t ;$ \\
$R_{c m t}$ & $\begin{array}{l}\text { rendimento da } c \text {-ésima cultura, no } m \text {-ésimo município do estado, no período } t ; \\
\gamma_{c m t}\end{array} \quad \begin{array}{l}\text { proporção da área cultivada com a } c \text {-ésima cultura no } m \text {-ésimo município, na área } \\
\text { cultivada da } c \text {-ésima cultura no estado }\left(\mathrm{A}_{c m t} / \mathrm{A}_{c t}\right) \text {, no período } t ;\end{array}$ \\
$\beta_{c m t}$ & $\begin{array}{l}\text { proporção da área total cultivada com a } c \text {-ésima cultura no } m \text {-ésimo município, } \\
\text { na área total do estado }\left(\mathrm{A}_{c m t} / \mathrm{A}_{m t}\right), \text { no período } t ;\end{array}$ \\
& $\begin{array}{l}\text { é o coeficiente que mensura a modificação na área total cultivada das culturas } \\
\text { entre o período inicial e final }\left(\mathrm{A}_{f} / \mathrm{A}_{i}\right) .\end{array}$ \\
\hline
\end{tabular}

O presente trabalho utilizará o modelo para verificar as alterações na produção em decorrência dos efeitos de composição (área e substituição), isto é, a variação da área plantada para verificar a substituição de culturas, dentro da variação da área total utilizada. Assim, conforme Paranaíba e Pires (2009), a variação da área ocupada por determinada cultura no sistema de produção é expressa por:

$$
\left(A_{c f}-A_{c i}\right)
$$

Considerando $\lambda$ como o coeficiente que mede a modificação do tamanho do sistema, a variação da área ocupada do sistema pode ser decomposta no efeito escala e no efeito substituição:

$$
\begin{gathered}
\left(\lambda A_{c i}-A_{c i}\right) \text { é o efeito escala (EE); } \\
\left(A_{c f}-\lambda A_{c i}\right) \text { é o efeito substituição (ES); }
\end{gathered}
$$

ou seja,

$$
\left(A_{c f}-A_{c i}\right)=\left(\lambda A_{c i}-A_{c i}\right)+\left(A_{c f}-\lambda A_{c i}\right)
$$

Verifica-se dentro do sistema de produção o efeito escala, visto que o somatório do efeito substituição é nulo, ou seja:

$$
\sum_{c=1}^{n}\left(A_{c f}-A_{c i}\right)=0
$$

Esses efeitos também podem ser apresentados na forma de taxas anuais de crescimento, seguindo os mesmo procedimentos da transformação anteriormente demonstrada. Isso significa que, dividindo-se ambos os lados da equação 3 por $\left(A_{c f}-A_{c i}\right)$ tem-se: 


$$
1 \equiv \frac{\left(A_{c i}-A_{c i}\right)}{\left(A_{c f}-A_{c i}\right)} \mathbf{E} \mathbf{A}+\frac{\left(A_{c f}-A_{c i}\right)}{\left(A_{c f}-A_{c i}\right)} \mathbf{E} \mathbf{A}
$$

Multiplicando-se ambos os lados da identidade 5 pelo efeito área (EA) expresso em taxa de crescimento ao ano (\%), definido anteriormente, tem-se:

$$
E A \%_{a a} \equiv \frac{\left(A_{c i}-A_{c i}\right)}{\left(A_{c f}-A_{c i}\right)} \mathbf{E} \mathbf{A}+\frac{\left(A_{c f}-A_{c i}\right)}{\left(A_{c f}-A_{c i}\right)} \mathbf{E} \mathbf{A}
$$

em que:

$$
\begin{aligned}
& \frac{\left(A_{c i}-A_{c i}\right)}{\left(A_{c f}-A_{c i}\right)} \mathbf{E A} \\
& \frac{\left(A_{c f}-A_{c i}\right)}{\left(A_{c f}-A_{c i}\right)} \mathbf{E A}
\end{aligned}
$$

O efeito rendimento será utilizado para analisar a vantagem tecnológica locacional de competitividade dos municípios analisados, para tanto, será utilizado na forma de taxa anual de variação do rendimento, dada pela seguinte expressão:

$$
R \% \equiv\left(\sqrt[f]{\frac{R_{c f}}{R_{c i}}}\right) 100
$$

onde $f$ à quantidade de anos do período em análise.

Também será utilizado o componente diferencial do modelo "shift-share", na forma de sua taxa de crescimento ao ano relacionado às vantagens locacionais comparativas, especificamente o efeito localização geográfica, conforme descrito na expressão 7 .

$$
\begin{gathered}
Q_{c f}-Q_{c i}=\sum_{m=1}^{k}\left(\gamma_{c m f} A_{c f} R_{c m f}\right)-\sum_{m=1}^{k}\left(\gamma_{c m i} A_{c f} R_{c m f}\right) \\
r \equiv\left(\sqrt[f]{\frac{Q_{c f}}{Q_{c i}}}\right) 100
\end{gathered}
$$

sendo $f$ a quantidade de anos do período em análise e $r$ a taxa anual média de variação da produção da $c$-ésima cultura, o efeito localização geográfica (EL), expresso em taxa de crescimento ao ano, em porcentagem é obtido com a seguinte expressão:

$$
\frac{\left(Q_{c f}-Q_{c f}^{A R}\right)}{\left(Q_{c f}-Q_{c i}\right)} r
$$

\subsection{Cálculo do efeito composição da produção}

O cálculo do efeito composição da produção é efetuado pela variação do valor da produção para um dado conjunto de culturas, assim tem-se:

$$
E C=\sum_{c=1}^{n}\left(\beta_{c m f} A_{m f} R_{c m f} P_{c}\right)-\sum_{m=1}^{k}\left(\beta_{c m i} A_{m f} R_{c m f} P_{c}\right)
$$

Percebe-se que o efeito composição corresponde à diferença entre duas médias ponderadas das variáveis rendimento e preço, mudando o fator de ponderação $\beta_{c m i}$ para $\beta_{c m f}$. Portanto, o EC é positivo 
se aumentar a participação das lavouras com alto valor da produção por unidade de área, permitindo, através de sua análise identificar vantagens econômicas decorrentes da composição produtiva na região (Yokoyama, 1992).

\subsection{Coleta e tratamento dos dados}

Os dados de área e rendimento foram coletados do IBGE-PAM (2010), referentes ao período 2000 a 2009, para todos os municípios do estado de Goiás. Para eliminar o efeito de variações sazonais na produção, foi utilizada a média dos três primeiros anos, ou seja, entre 2000 e 2002, como período inicial e dos três últimos anos, 2007 a 2009, como período final.

Os dados referentes à área de pastagens foram obtidos por meio dos censos agropecuários ${ }^{5}$ de 1975 , 1985, 1995 e 2006, os quais foram submetidos à análise de regressão exponencial não-linear para determinação dos valores correspondentes ao período analisado, conforme Nogueira (2009). ${ }^{6}$ Tal análise foi executada para todos os municípios do estado de Goiás.

O valor bruto da produção pecuária foi estimado como valor relativo à unidade bovina, a partir dos resultados de Tavares et alii (2009). O autor estabelece a rentabilidade econômica da bovinocultura de corte no estado de Goiás, por meio da configuração de propriedades pecuárias de tipo padrão para 10 regiões no Estado e, para cada propriedade, determina a receita bruta total a partir da quantidade de animais existentes em cada propriedade padrão.

Assim, o presente trabalho elaborou uma média ponderada das regiões analisadas por Tavares et alii (2009), e estimou o valor de $R \$ 659,80$ como valor bruto da produção pecuária equivalente à unidade de cabeça bovina por município, uma vez que a quantidade anual de cabeças bovinas por município é disponibilizada pelo IBGE nas séries históricas.

\section{RESULTADOS E DISCUSSÃO}

Para a análise dos impactos da competição pelo uso do solo a partir da expansão sucroalcooleira no estado de Goiás, os resultados serão apresentados em três etapas. Primeiramente, faz-se uma abordagem global na qual o estado de Goiás é analisado pelo modelo "shift-share", através da decomposição da variação da área cultivada em efeitos escala e substituição, assim como das taxas de crescimento da produção. $O$ efeito composição de culturas é analisado através da variação do valor bruto da produção de cada cultura e da somatória do conjunto de culturas.

A seguir, esses resultados são discriminados a nível municipal, evidenciando os municípios com maior especialização na cultura de cana-de-açúcar e os efeitos dessa especialização na composição agropecuária do município e, consequentemente, nos remanescentes florestais.

Por fim a análise é agrupada a nível microrregional, destacando-se as microrregiões de maior concentração dos municípios especializados e sobrepondo este resultado ao Sistema de Informações Geográficas - SIG de classes de risco de deficiência hídrica para a cultura da cana-de-açúcar (Silva et alii, 2008), permitindo discutir os impactos da especialização no uso consuntivo de água.

\subsection{Expansão da cultura da cana-de-açúcar no estado de Goiás}

O estado de Goiás, em 2009 apresentou em sua composição de uso do solo, o predomínio de pastagens e culturas temporárias. Conforme apresentado na Tabela 1 , observa-se que, com $0,18 \%$ de par-

\footnotetext{
${ }^{5}$ Para os demais anos a PAM - IBGE só fornece a quantidade de cabeças anual em cada município.

${ }^{6} \mathrm{O}$ autor utiliza os dados censitários que fornecem a área de pastagem e a quantidade de cabeças bovinas para os anos 1975, 1985, 1995 e 2006, para obter a produtividade das pastagens em cada ano de realização do censo, a partir destes resultados estima a equação que fornece a produtividade das pastagens para os demais anos compreendidos entre os censos. Com esses resultados é possível estimar a área de pastagens a cada ano para qualquer município, através do quociente: produtividade / número de cabeças.
} 
ticipação na área agropecuária, as culturas permanentes são pouco significativas, motivo pelo qual se optou por excluir as mesmas da análise deste trabalho.

Tabela 1: Distribuição relativa do uso do solo para agropecuária no estado de Goiás em 2009

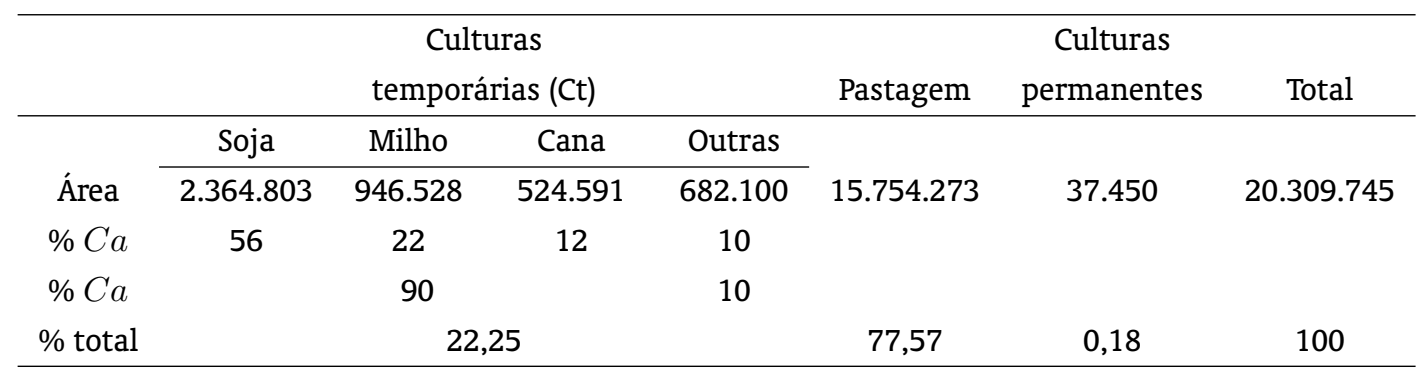

Fonte: IBGE-PAM (2010) - Elaboração autor.

Na distribuição das culturas temporárias dentro do Estado, as culturas de soja, milho e cana-deaçúcar ocupam juntas aproximadamente $90 \%$ do uso do solo para esta categoria (Tabela 1) dessa forma constituindo, junto com as pastagens, $98,9 \%$ das fontes de substituição entre cultivos no período analisado.

Ao longo do período 2000-2009, observa-se, conforme apresentado na Tabela 2, uma diminuição da área cultivada no Estado pelo conjunto das culturas analisadas. Essa retração pode ser explicada pelo efeito da variação das categorias que não foram compreendidas na análise, tais como matas e florestas, parques, lagos, áreas urbanas e culturas permanentes. Tais categorias foram excluídas por não serem significativas, no caso de culturas permanentes, ou por não haver dados disponíveis que permitam quantificá-las com precisão similar às demais.

As culturas que apresentaram maior expansão de área cultivada no Estado, entre 2003 e 2009, foram: soja com 591.974 ha, cana-de-açúcar com 376.822 ha e milho com 70.897 ha, juntas estas culturas substituíram $85,47 \%$ da área cedida pelas culturas em retração, sendo a cana-de-açúcar responsável por $30 \%$ da substituição total. A cultura do sorgo teve a terceira maior expansão, entretanto, por se tratar de uma cultura tipicamente de segunda safra, não disputa área com as demais culturas, pois, normalmente, esta é plantada em sucessão as culturas de milho e soja.

Analogamente, as culturas que apresentaram maior retração foram: pastagens, com 1.513.053 ha, algodão 31.589 ha, arroz 18.579 ha e feijão 4.001 ha, cedendo um total de 1.267.495 ha.

A cultura de girassol também apresentou expressiva expansão de área, entretanto, os dados do IBGE indicam que essa cultura entrou no Estado a partir de 2005, substituindo outras culturas, sem participar do efeito escala observado no período 2000-2009.

A análise da taxa de expansão da produção das culturas (Tabela 3) revela que aquelas que apresentaram maior taxa foram respectivamente: girassol, com 190,8\%, amendoim, com 23,3\% e cana-de-açúcar, com $16,4 \%$. Salientando o fato de que a cultura do girassol entra no Estado a partir de 2005 e a cultura do amendoim apresenta pouca expressão, 0,008\% de 20.309 .745 ha cultivados (IBGE-PAM, 2010), conclui-se que a cana-de-açúcar apresentou a maior taxa significativa de expansão da produção, sendo que esta taxa é explicada sobretudo pelo efeito substituição, com 15,2\% dos 16,4\% de crescimento anual apresentado.

Apesar da redução da área de pastagens apresentada na Tabela 2, verifica-se, conforme apresentado na Tabela 3, um aumento de $0,8 \%$ ao ano na quantidade de rebanho bovino no Estado, explicado pelo aumento de $1,7 \%$ ao ano no rendimento das pastagens em detrimento à redução de $0,9 \%$ ao ano em área das mesmas. 
Tabela 2: Decomposição da variação da área (ha) ocupada em efeitos escala e substituição no estado de Goiás, 2000 a 2009

\begin{tabular}{|c|c|c|c|}
\hline Culturas & AF-AI & $\mathrm{EE}$ & ES \\
\hline Soja & 591.974 & -28.555 & 620.529 \\
\hline Cana-de-açúcar & 376.822 & -2.371 & 379.194 \\
\hline Sorgo & 143.295 & -2.454 & 145.750 \\
\hline Milho & 70.897 & -14.513 & 85.411 \\
\hline Girassol & 14.859 & 0 & 14.859 \\
\hline Mandioca & 9.127 & -299 & 9.426 \\
\hline Trigo & 5.784 & -249 & 6.033 \\
\hline Tomate & 2.708 & -193 & 2.900 \\
\hline Batata-inglesa & 1.997 & -46 & 2.043 \\
\hline Amendoim & 1.259 & -6 & 1.264 \\
\hline Cebola & 857 & -6 & 863 \\
\hline Mamona & 698 & -5 & 703 \\
\hline Melancia & 442 & -113 & 555 \\
\hline Alho & 45 & -33 & 78 \\
\hline Sub total & 1.220 .764 & -48.843 & 1.269 .608 \\
\hline Batata-doce & -109 & -4 & -104 \\
\hline Abacaxi & -357 & -41 & -317 \\
\hline Ervilha & -557 & -19 & -538 \\
\hline Cevada & -1.173 & -20 & -1.153 \\
\hline Feijão & -4.001 & -2.281 & -1.720 \\
\hline Arroz & -18.579 & -2.141 & -16.437 \\
\hline Algodão & -31.589 & -1.752 & -29.837 \\
\hline Pastagem & -1.513 .053 & -293.552 & -1.219 .501 \\
\hline Sub total & -1.569 .418 & -299.810 & 1.269 .608 \\
\hline TOTAL & -348.652 & -348.652 & 0 \\
\hline
\end{tabular}

Fonte: Resultados da pesquisa. 
Tabela 3: Taxa média anual de crescimento da: Quantidade produzida, efeitos área (efeitos escala e substituição) e rendimento e variação do valor bruto da produção (VVBP) das culturas selecionadas no estado de Goiás de 2000 a 2009

\begin{tabular}{lcccccc}
\hline \multicolumn{1}{c}{ Culturas } & $\mathrm{EQP} \%$ & $\mathrm{EA} \%_{a a}$ & $\mathrm{EE} \%_{a a}$ & $\mathrm{ES} \%_{a a}$ & $\mathrm{ER} \%_{a a}$ & $\mathrm{VVBP}$ \\
\hline Soja & 4,1 & 3,3 & $-0,2$ & 3,5 & 0,8 & -19.648 .332 \\
Cana-de-açúcar & 16,4 & 15,2 & $-0,1$ & 15,2 & 1,3 & 962.216 .188 \\
Sorgo & 11,3 & 6,9 & $-0,1$ & 7,0 & 4,4 & 48.247 .594 \\
Milho & 2,8 & 0,8 & $-0,2$ & 1,0 & 2,0 & -365.793 .599 \\
Girassol & 190,8 & 0 & 0 & 190,8 & 0,0 & 11.949 .840 \\
Mandioca & 6,1 & 4,5 & $-0,1$ & 4,6 & 1,6 & 10.318 .401 \\
Trigo & 16,0 & 2,3 & $-0,1$ & 2,4 & 13,7 & 1.251 .428 \\
Tomate & 4,1 & 2,3 & $-0,2$ & 2,4 & 1,8 & -24.403 .032 \\
Batata-inglesa & 9,2 & 5,6 & $-0,1$ & 5,7 & 3,6 & 23.273 .888 \\
Amendoim & 23,3 & 16,3 & $-0,1$ & 16,4 & 6,9 & 2.369 .183 \\
Cebola & 14,9 & 15,7 & $-0,1$ & 15,8 & $-0,8$ & 25.500 .170 \\
Mamona & 15,3 & 13,6 & $-0,1$ & 13,7 & 1,7 & 466.894 \\
Melancia & 8,0 & 0,5 & $-0,1$ & 0,7 & 7,4 & -17.185 .600 \\
Alho & 4,7 & 0,2 & $-0,2$ & 0,4 & 4,5 & -17.253 .511 \\
Batata-doce & $-6,2$ & $-6,0$ & $-0,2$ & $-5,8$ & $-0,1$ & -649.954 \\
Abacaxi & $-1,4$ & $-1,8$ & $-0,2$ & $-1,6$ & 0,3 & -21.047 .574 \\
Ervilha & $-6,3$ & $-7,0$ & $-0,2$ & $-6,8$ & 0,7 & -2.474 .273 \\
Cevada & $-100,0$ & $-100,0$ & $-1,7$ & $-98,3$ & 0,0 & -2.569 .926 \\
Feijão & 1,8 & $-0,3$ & $-0,2$ & $-0,1$ & 2,1 & -176.879 .020 \\
Arroz & 0,7 & $-1,6$ & $-0,2$ & $-1,4$ & 2,3 & -80.695 .447 \\
Algodão & $-0,7$ & $-3,5$ & $-0,2$ & $-3,3$ & 2,8 & -364.898 .164 \\
\hline & & Subtotal culturas temporárias & & -7.904 .845 \\
Bovinos & 0,8 & $-0,9$ & $-0,2$ & $-0,8$ & 1,7 & 906.995 .592 \\
\hline & & TOTAL & & & & 899.090 .746 \\
\hline
\end{tabular}

Fonte: Resultados da pesquisa. 
Com relação à variação do valor bruto da produção, a Tabela 3 mostra que, apesar do fato da cana ter contribuído com um incremento de R\$ 962.216.188, a composição da produção de culturas temporárias, no final do período, gerou uma perda de R\$ 7.904.845 para o Estado, explicada principalmente pela diminuição da participação relativa do algodão e do milho nesta composição. Entretanto, o valor adicionado pelo aumento do rebanho, R\$ 906.995.592, foi suficiente para obtenção de um saldo positivo de R\$ 899.090.746 na composição total da produção agropecuária no Estado.

\subsection{Análise da especialização em cana-de-açúcar dos municípios do estado de Goiás}

Para identificar os municípios com especialização produtiva em cana-de-açúcar, primeiramente foi utilizado o Quociente de Localização. Segundo este indicador, 58 municípios apresentaram coeficiente maior que 1, indicando que a concentração desta cultura é superior à média do Estado. A seguir, esses municípios foram dispostos em um ranking decrescente para o Quociente de Localização e para o Coeficiente de Especialização e, em ordem crescente para o Índice de Theil. Essa organização relaciona em, ordem decrescente, os municípios com maior indicação de especialização e, conforme Lopes (2001), a análise conjunta dos indicadores permite resultados mais conclusivos.

Uma vez realizada tal ordenação, executou-se a análise de correlação entre os indicadores e entre grupos de municípios segundo a seguinte composição: Total de municípios $(n=58), 50 \%$ do total ( $n=$ $29), 1 / 3$ do total $(n=19), 15$ mais especializados e 10 mais especializados, a fim de identificar a maior correlação entre todos os indicadores e, assim selecionar o grupo que mais represente os municípios especializados.

Executou-se também uma análise de correlação de Pearson entre o Índice de Theil e as frações: $\left(C_{n} / C_{t}\right)=$ total de área colhida com cana/total de área colhida com culturas temporárias e $\left(C_{n} /\right.$ tot $)=$ total de área colhida com cana/ (total de área de pastagens + total área colhida culturas temporárias), já que, conforme dito anteriormente (Lopes, 2001), o Índice de Theil permite identificar a estrutura de especialização produtiva local sem compará-la a uma região padrão, permitindo assim, analisar a influência das pastagens, categoria com maior representatividade no total de área agropecuária, no nível de especialização de cada município.

A Tabela 4 apresenta os resultados das correlações. Segundo estes resultados, a ordenação que apresentou maior correlação entre os indicadores foi a que organiza os municípios em ordem crescente para o Índice de Theil. Quando dispostos nesta ordem, observou-se correlação significativa, a 99\% de confiabilidade, entre QL e CE para metade dos municípios e significativa, a 95\% de confiabilidade, entre todos os indicadores para $1 / 3$ dos municípios.

Para aumentar a abrangência da análise, optou-se por selecionar a metade dos municípios, ordenados pelo Índice de Theil, os quais são apresentados na Tabela 5. Os mesmos foram organizados em ordem decrescente para o Quociente de Localização, por ser esta a disposição de maior correlação entre este quociente e o Coeficiente de Especialização.

A Tabela 5 apresenta ainda, para cada município, as seguintes relações entre as categorias de uso do solo: área colhida de culturas temporárias $\left(C_{t}\right)$ no total de área agropecuária (Tot), composto por $C t+$ área de pastagens; área colhida de cana-de-açúcar $\left(C_{n}\right)$ no total da área colhida de culturas temporárias $\left(C_{t}\right)$ e área colhida de cana-de-açúcar $\left(C_{n}\right)$ no total de área agropecuária (Tot). Estes resultados foram submetidos à análise de correlação, a qual é apresentada na Tabela 6 .

Os resultados apresentados na Tabela 6 indicam, segundo o CE, que a participação das culturas temporárias no total das atividades agropecuárias é mais significativa que a participação da cana no total, sugerindo que, em relação à média do estado de Goiás, as culturas temporárias exercem maior influência na especialização do que a cana isoladamente e, isto se deve ao fato da elevada participação da área de pastagens no estado, 77,6\% (Tabela 1), e da maior participação da soja e do milho em relação à cana na composição das culturas temporárias. Este resultado confirma a influência da região padrão no Coeficiente de Especialização. 
Tabela 4: Coeficientes de correlação de Pearson entre os indicadores de localização e especialização utilizados

\begin{tabular}{ccc|cc|cc}
\hline & \multicolumn{2}{c}{ QL $\downarrow$} & \multicolumn{2}{c}{ CE $\downarrow$} & \multicolumn{2}{c}{ IT $\downarrow$} \\
\hline & \multicolumn{4}{c}{ Correl } \\
Grupo & QLCE & QLIT & QLCE & QLIT & QLCE & QLIT \\
Total $^{7}$ & 0,44 & 0,24 & 0,44 & 0,24 & 0,44 & 0,24 \\
$50 \%$ & $0,55^{* *}$ & 0,15 & $0,55^{* *}$ & 0,15 & $0,55^{* *}$ & 0,15 \\
$1 / 3$. & $0,69^{* *}$ & 0,11 & 0,32 & $-0,39$ & $0,97^{* *}$ & $0,49^{*}$ \\
$15+$ & $0,75^{* *}$ & 0,15 & 0,25 & $-0,46^{*}$ & $0,97^{* *}$ & $0,52^{* *}$ \\
$10+$ & $0,62^{* *}$ & $-0,04$ & 0,16 & $-0,51^{* *}$ & $0,94^{* *}$ & $0,43^{*}$ \\
\hline
\end{tabular}

Fonte: Resultados da pesquisa.

${ }^{*}$ Correlation is significant at the 0.05 level (2-tailed).

** Correlation is significant at the 0.01 level (2-tailed).

De fato, quando essas relações são analisadas pelo Índice de Theil, o qual elimina a comparação com a região padrão, verifica-se que a maior participação das culturas temporárias na composição agropecuária do município está correlacionada à maior diversificação do mesmo, novamente tendo em vista a elevada participação da agropecuária na maioria dos municípios apresentados na Tabela 4, ou seja, dos 29 municípios, 17 apresentam participação das culturas temporárias inferior a 50\% do total.

Finalmente, a elevada correlação do Índice de Theil para a participação da cana-de-açúcar na composição das culturas temporárias, sugere que quanto maior a participação da cana nas culturas temporárias, mais especializado é o município. Esta análise, quando comparada a não significância da correlação da participação da cana no total agropecuário, permite inferir que os municípios mais especializados em cana são, também mais especializados em culturas temporárias, confirmando a hipótese de Castro et alii (2007), de que a expansão sucroalcooleira em Goiás estaria se direcionando para áreas de culturas temporárias em detrimento às áreas de pastagens.

Conforme exposto anteriormente, os indicadores apresentados até o momento permitem apenas uma análise estática, para um ano agrícola, não refletindo a evolução da dinâmica dos setores agropecuários. Diante disso, a seguir são apresentados os resultados do modelo "shift-share" para a dinâmica de competição pelo uso do solo entre os complexos.

\subsection{Análise da dinâmica de competição pelo uso do solo entre os complexos da cana-de-açúcar, bovinocultura, soja e milho}

Uma vez que a dinâmica de competição pelo uso do solo será analisada segundo a maior concentração da atividade de produção de cana-de-açúcar em relação à totalidade da produção agropecuária em cada município, adotou-se como indicador de referência, para as correlações, o Quociente de Localização.

A Tabela 7 apresenta os resultados do modelo Shift-Share com os indicadores analisados para cada município. A fim de tornar mais clara a exposição, a seguinte legenda define as variáveis utilizadas. 
Tabela 5: Municípios com maior especialização local para cana-de-açúcar, indicadores de localização e especialização e relação entre as categorias de uso do solo

\begin{tabular}{|c|c|c|c|c|c|c|}
\hline Municípios & QL & $\mathrm{CE}$ & IT & $\mathrm{C}_{t} /$ tot & $\mathrm{C}_{n} / \mathrm{C}_{t}$ & $\mathrm{C}_{n} /$ tot \\
\hline Gouvelândia & 18,91 & 0,46 & 0,41 & 0,55 & 0,88 & 0,48 \\
\hline Porteirão & 18,61 & 0,62 & 0,58 & 0,82 & 0,58 & 0,48 \\
\hline Maurilândia & 14,35 & 0,38 & 0,49 & 0,55 & 0,67 & 0,37 \\
\hline Nova Glória & 13,68 & 0,33 & 0,34 & 0,38 & 0,93 & 0,35 \\
\hline São Luíz do Norte & 11,69 & 0,29 & 0,4 & 0,36 & 0,84 & 0,30 \\
\hline Santa Helena de Goiás & 11,33 & 0,58 & 0,64 & 0,77 & 0,38 & 0,29 \\
\hline Rialma & 10,29 & 0,25 & 0,33 & 0,30 & 0,87 & 0,26 \\
\hline Americano do Brasil & 9,70 & 0,33 & 0,54 & 0,45 & 0,55 & 0,25 \\
\hline Carmo do Rio Verde & 9,66 & 0,24 & 0,39 & 0,32 & 0,77 & 0,25 \\
\hline Turvelândia & 8,75 & 0,36 & 0,60 & 0,57 & 0,39 & 0,22 \\
\hline Ipiranga de Goiás & 8,47 & 0,22 & 0,36 & 0,28 & 0,77 & 0,22 \\
\hline Anicuns & 7,92 & 0,23 & 0,42 & 0,32 & 0,63 & 0,20 \\
\hline Cachoeira Dourada & 7,18 & 0,31 & 0,60 & 0,52 & 0,35 & 0,18 \\
\hline São Simão & 7,01 & 0,16 & 0,28 & 0,21 & 0,84 & 0,18 \\
\hline Inhumas & 6,75 & 0,19 & 0,38 & 0,26 & 0,67 & 0,17 \\
\hline Jandaia & 6,75 & 0,15 & 0,38 & 0,28 & 0,63 & 0,17 \\
\hline Quirinópolis & 6,68 & 0,15 & 0,40 & 0,30 & 0,57 & 0,17 \\
\hline Bom Jesus de Goiás & 6,67 & 0,45 & 0,61 & 0,65 & 0,26 & 0,17 \\
\hline Edéia & 6,21 & 0,60 & 0,54 & 0,80 & 0,20 & 0,16 \\
\hline Castelândia & 6,12 & 0,33 & 0,61 & 0,54 & 0,29 & 0,16 \\
\hline Vicentinópolis & 5,86 & 0,47 & 0,56 & 0,67 & 0,23 & 0,15 \\
\hline Rubiataba & 5,69 & 0,17 & 0,24 & 0,66 & 0,85 & 0,15 \\
\hline Goianésia & 5,56 & 0,13 & 0,32 & 0,21 & 0,67 & 0,14 \\
\hline São Patrício & 5,47 & 0,16 & 0,27 & 0,18 & 0,76 & 0,14 \\
\hline Itumbiara & 5,44 & 0,25 & 0,55 & 0,46 & 0,31 & 0,14 \\
\hline Paranaiguara & 4,99 & 0,18 & 0,20 & 0,14 & 0,92 & 0,13 \\
\hline Goiatuba & 4,92 & 0,32 & 0,59 & 0,53 & 0,24 & 0,13 \\
\hline Vila Propício & 4,87 & 0,10 & 0,35 & 0,23 & 0,54 & 0,12 \\
\hline Nazário & 4,80 & 0,17 & 0,41 & 0,28 & 0,44 & 0,12 \\
\hline
\end{tabular}

Fonte: Resultados da pesquisa. 
Tabela 6: Coeficientes de correlação de Pearson entre os indicadores de localização e especialização e as categorias de uso do solo

\begin{tabular}{cccc}
\hline & QL & CE & IT \\
\hline C $t /$ Tot & 0,357 & $0,881^{* *}$ & $0,737^{* *}$ \\
$C_{n} / C_{t}$ & 0,357 & $-0,435^{*}$ & $-0,833^{* *}$ \\
$C_{n} /$ Tot & $1,000^{* *}$ & $0,554^{* *}$ & 0,155 \\
\hline
\end{tabular}

Fonte: Resultados da pesquisa.

${ }^{*}$ Correlation is significant at the

0.05 level (2-tailed).

** Correlation is significant at the

0.01 level (2-tailed).

\begin{tabular}{l}
\hline QL - quociente de localização \\
\hline EA - Efeito área = área final - área inicial \\
\hline EL\% - efeito localização geográfica - evolução percentual ao ano \\
\hline EA\% - efeito área - evolução percentual ao ano \\
\hline ER\% - afeito rendimento - evolução percentual ao ano \\
\hline Cn - cana-de-açúcar \\
\hline P - pastagens \\
\hline S - soja \\
\hline M - milho \\
\hline Oc - outras culturas temporárias \\
\hline Saldo - somatória da variação da área total agropecuária no município \\
\hline
\end{tabular}

O efeito área para a cultura da cana está também negativamente correlacionado ao efeito área para outras culturas, indicando que a expansão da cana, além de ocupar áreas de soja, ocupa áreas de outras culturas temporárias, conforme comprovado também na análise de correlação da taxa de expansão anual da cana com o efeito área do milho.

A correlação entre a taxa anual de expansão da cana (EA $C_{n} \%$ ) e o efeito localização geográfica, para esta cultura, indica que a maior expansão da mesma ocorre em municípios com maior efeito localização geográfica, permitindo assim, identificar tais municípios e investigar os fatores locais que promovem vantagem comparativa aos mesmos.

Observa-se na Tabela 8 elevada correlação positiva entre o efeito área de pastagens e o saldo final das áreas agropecuárias, entretanto, um saldo final positivo indica que para o aumento total da área agropecuária necessita-se de um estoque de terras, o qual não foi apresentado nesta analise. Este estoque corresponde à:

(i) áreas urbanas,

(ii) mananciais hídricos,

(iii) terras inaproveitáveis,

(iv) culturas permanentes e, 


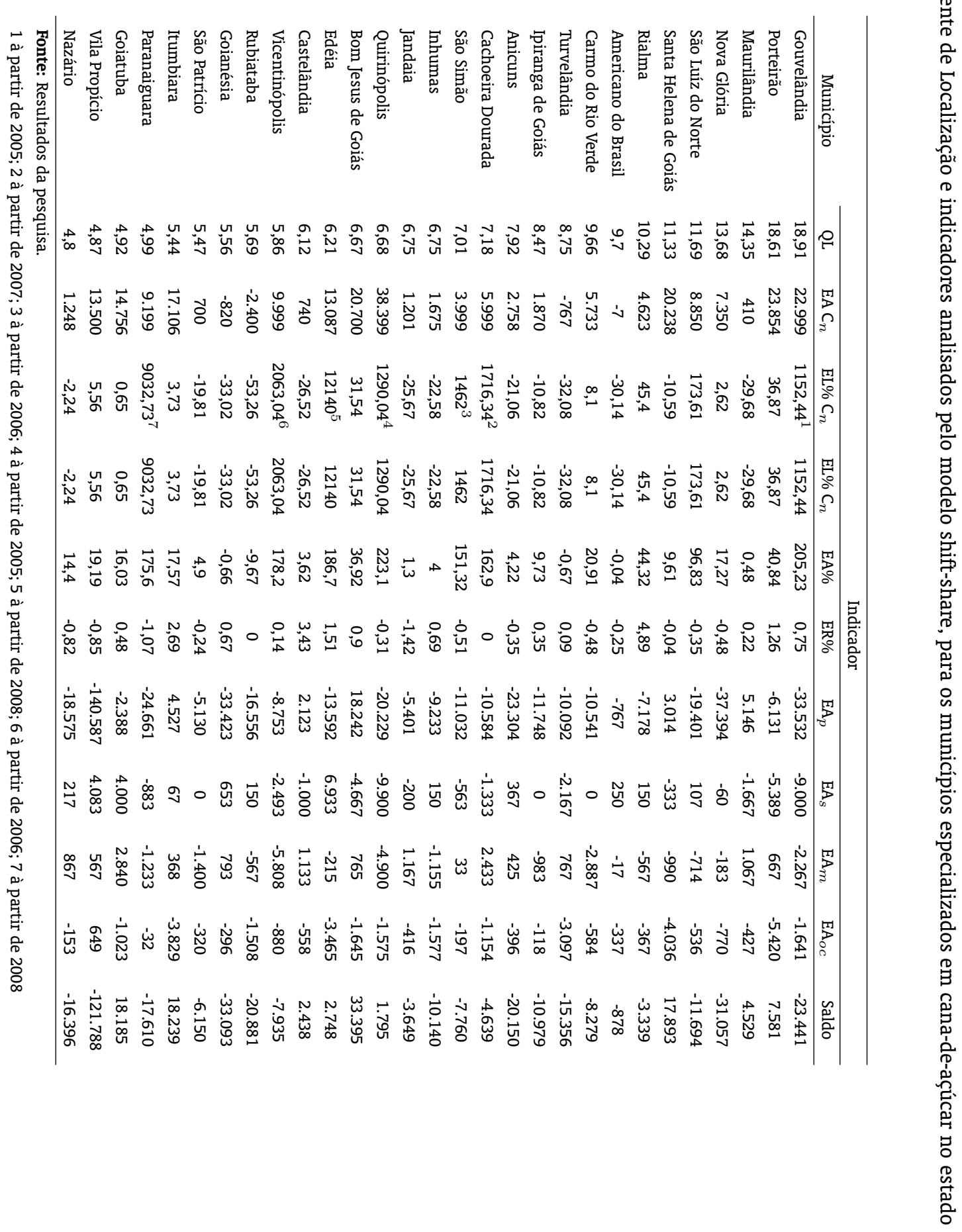


(v) remanescentes florestais, dos quais, apenas os remanescentes florestais e as culturas permanentes constituem áreas com potencial de utilização.

Uma vez que a área de culturas permanentes no estado de Goiás é insignificante, $0,18 \%$ (Tabela 1), a correlação entre o efeito área de pastagens e o saldo final positivo indica que as pastagens são as maiores responsáveis pelo desflorestamento nos municípios analisados. De fato, inversamente, o efeito área das outras culturas temporárias, negativamente correlacionado ao saldo, reforça esta hipótese.

Para analisar o efeito da especialização no uso consuntivo da água, utilizou-se como referência os resultados do trabalho de Silva et alii (2008), o qual fornece o mapa com as classes de risco de disponibilidade hídrica para atender a demanda da cultura da cana-de-açúcar.

Tabela 8: Coeficientes de correlação de Pearson entre as variáveis utilizadas no modelo shift-share

\begin{tabular}{lcccccccccc}
\hline & QL & EA C $_{n}$ & EL C $_{n} \%$ & EA C $_{n} \%$ & ER C $_{n} \%$ & EA P & EA S & EA M & EA Oc & Saldo \\
\hline QL & 1 & 0,257 & $-0,189$ & 0,065 & 0,1 & 0,086 & $-0,465^{*}$ & $-0,065$ & $-0,35$ & 0,101 \\
EA C $_{n}$ & 0,257 & 1 & 0,151 &, $528^{* *}$ & 0,067 & $-0,068$ & $-0,512^{* *}$ & $-0,34$ & $-0,487^{* *}$ & 0,182 \\
EL C $_{n} \%$ & $-0,189$ & 0,151 & 1 & $0,618^{* *}$ & $-0,019$ & $-0,029$ & 0,26 & $-0,144$ & $-0,136$ & 0,041 \\
EA C $_{n} \%$ & 0,065 & $0,528^{* *}$ &, $618^{* *}$ & 1 & $-0,069$ & $-0,063$ & $-0,369^{*}$ & $-0,485^{* *}$ & $-0,062$ & 0,045 \\
ER C $_{n} \%$ & 0,1 & 0,067 & $-0,019$ & $-0,069$ & 1 & 0,293 & 0,008 & 0,107 & $-0,289$ & 0,319 \\
EA P & 0,086 & $-0,068$ & $-0,029$ & $-0,063$ & 0,293 & 1 & $-0,213$ & 0,026 & $-0,339$ & $0,959^{* *}$ \\
EA S & $-0,465^{*}$ & $-0,512^{* *}$ & 0,26 & $-0,369^{*}$ & 0,008 & $-0,213$ & 1 & $0,428^{*}$ & 0,196 & $-0,24$ \\
EA M & $-0,065$ & $-0,34$ & $-0,144$ & $-0,485^{* *}$ & 0,107 & 0,026 & $0,428^{*}$ & 1 & $-0,019$ & 0,025 \\
EA Oc & $-0,35$ & $-0,487^{* *}$ & $-0,136$ & $-0,062$ & $-0,289$ & $-0,339$ & 0,196 & $-0,019$ & 1 & $-0,450^{*}$ \\
\hline Saldo & 0,101 & 0,182 & 0,041 & 0,045 & 0,319 & $0,959^{* *}$ & $-0,24$ & 0,025 & $-0,450^{*}$ & 1 \\
\hline
\end{tabular}

Fonte: Resultados da pesquisa.

* Correlation is significant at the 0.05 level (2-tailed).

** Correlation is significant at the 0.01 level (2-tailed).

A partir deste mapa o presente trabalho alocou os municípios com maior Quociente de Localização para a cultura da cana, distribuídos segundo sua localização nas microrregiões do estado de Goiás. Os resultados são apresentados na Figura 1.

$\mathrm{O}$ resultado indica que a maioria dos municípios com maiores Quocientes de Localização para a cultura da cana está distribuída em microrregiões com moderado a elevado risco de deficiência hídrica, revelando que os gestores empresariais do setor sucroalcooleiro não têm levado em consideração a disponibilidade hídrica para a instalação de seus empreendimentos e sugerindo conflitos pelo uso da água nestas regiões.

\subsection{Análise da expansão sucroalcooleira nas microrregiões do estado de Goiás}

A expansão sucroalcooleira nas microrregiões do estado de Goiás foi analisada segundo os efeitos área, decomposto em efeitos escala e substituição, e efeito localização geográfica, o qual quantifica o ganho ou perda de produção na região em relação à variação média observada para o Estado. Foi analisada ainda a variação do valor bruto da produção para as principais culturas e para o rebanho bovino (pastagens) a fim de identificar as vantagens econômicas de competitividade da cana-de-açúcar.

Segundo os resultados apresentados (Tabelas 9 e 10) as microrregiões com maior expansão da cultura da cana-de-açúcar foram a Meia Ponte e Quirinópolis com 102.473 ha e 81.845 ha de aumento de área plantada, respectivamente. Ambas apresentaram resultados positivos para o efeito localização geográfica, indicando que a expansão de área foi acima da média observada no estado de Goiás. Segundo a 
Figura 1: Classes de risco de deficiência hídrica para atender a demanda de irrigação da cultura de cana-de-açúcar no estado de Goiás e distribuição quantitativa dos municípios com maior quociente de localização

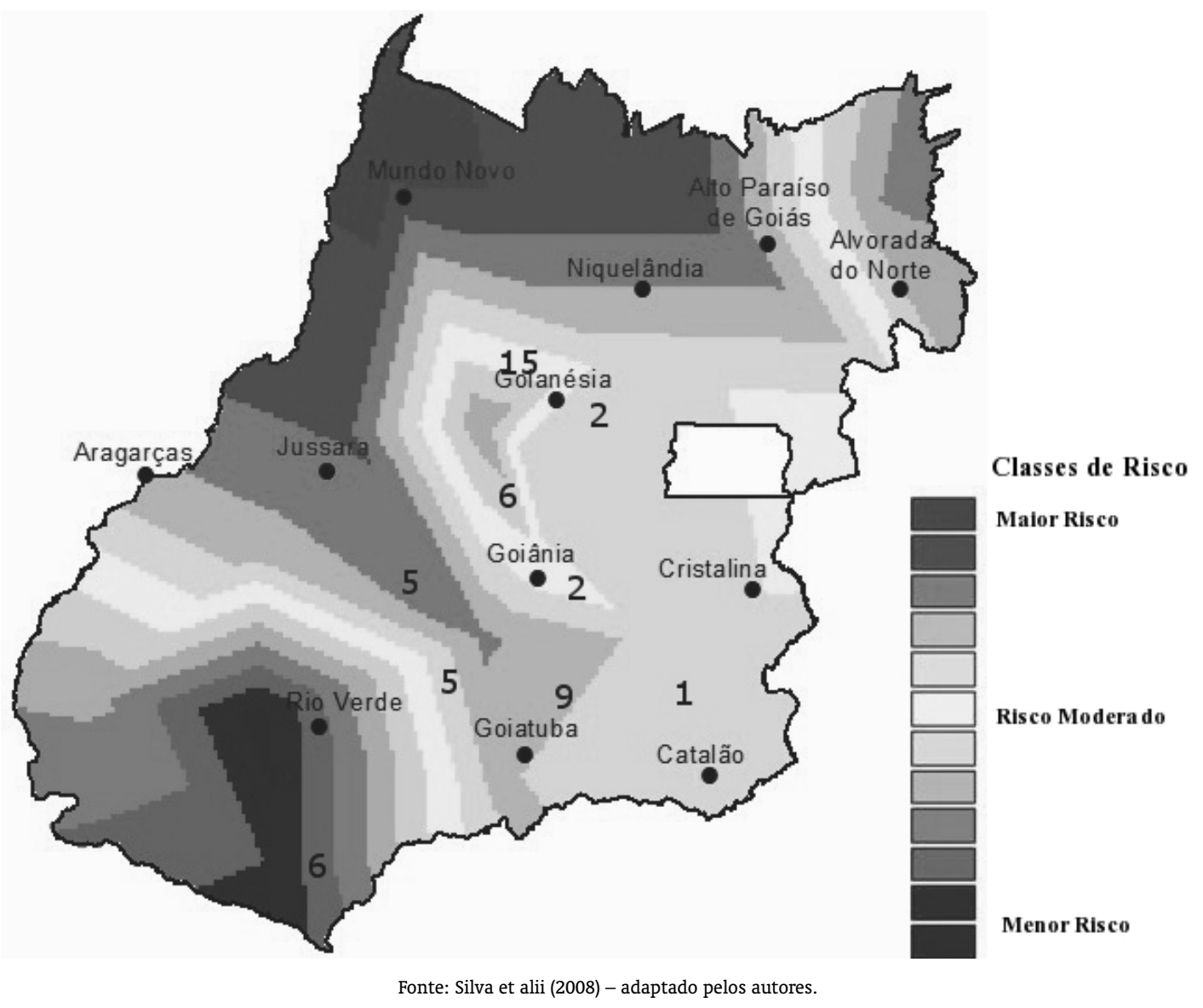

literatura (Miziara, 2009, Castro et alii, 2007, Moreira, 1996) esse efeito indica vantagens comparativas, provavelmente advindas de estímulos logísticos apresentados por essas regiões.

A microrregião Meia Ponte (Tabela 9) apresentou ainda, acentuada expansão da área de soja -40.512 ha, com forte retração da área de pastagens - 65.339 ha, porém não forte o suficiente para suprir a expansão das demais culturas, sugerindo o desmatamento de 85,9 mil ha apresentado no total da variação da área no período.

A cana-de-açúcar e o rebanho bovino foram responsáveis pelo saldo positivo de R\$ 92.532 .068 na composição final da produção da microrregião.

Os municípios que mais se destacaram foram Bom Jesus, Itumbiara e Goiatuba, com, respectivamente, 20.700 ha, 17.106 ha e 14.756 ha de expansão de área de cana-de-açúcar. Bom Jesus obteve a maior taxa de variação anual do efeito localização geográfica, 32\% de um total de $38 \%$ variação anual da produção. Itumbiara destacou-se pela expressividade do efeito rendimento, com uma taxa anual de aumento de 5,35\%, comparada a menos de $1 \%$ para os outros dois municípios. Essas estimativas indicam maior aptidão dos solos e maior aporte tecnológico na produtividade da terra neste município. 
Tabela 9: Decomposição da variação da área ocupada em efeitos escala e substituição e variação no valor bruto da produção (VVBP) na MR Meia Ponte 2000 a 2009

\begin{tabular}{lccccc}
\hline \multicolumn{1}{c}{ Culturas } & EA & EE & ES & EL & VVBP \\
\hline Algodão & -16.928 & -376 & -16.553 & -15.841 .115 & -57.598 .972 \\
Arroz & 3.837 & -129 & 3.965 & 10.623 .114 & 475.507 \\
Cana-de-açúcar & 102.473 & -229 & 102.702 & 3.884 .631 .142 & 289.205 .163 \\
Feijão & -548 & -94 & -454 & -1.915 .412 & -7.327 .961 \\
Milho & -1.763 & -1.275 & -488 & -66.035 .207 & -50.744 .487 \\
Soja & 40.512 & -4.604 & 45.116 & -153.572 .590 & -84.533 .019 \\
Pastagem & -65.339 & -18.059 & -47.280 & 14.838 & 15.976 .690 \\
Total & 85.910 & -25.176 & 111.086 & - & 92.532 .068 \\
\hline
\end{tabular}

Fonte: Resultados da pesquisa.

A microrregião Quirinópolis (Tabela 10) apresentou efeito escala zero para a cana-de-açúcar, indicando ser a expansão da cultura recente na região, ou seja, iniciando após 2004. A entrada desta cultura na região foi responsável pelo saldo positivo na composição de culturas no final do período, vez que a variação do valor bruto da produção foi negativa para todos os outros produtos, assim, com R\$ 267 milhões de saldo, a cultura recuperou a perda de participação de $\mathrm{R} \$ 174$ milhões dos demais produtos, gerando um superávit de $\mathrm{R} \$ 93$ milhões.

Nesta microrregião verifica-se ainda que a cana entrou em substituição as demais culturas apresentadas na Tabela 10. Os resultados sugerem ainda desmatamento da ordem de 14 mil hectares na microrregião. Os municípios de Quirinópolis e Gouvelândia destacaram-se com o aumento da quantidade produzida advindas exclusivamente de vantagens locacionais uma vez que a cultura inicia a participação nestes municípios a partir de 2006.

Tabela 10: Decomposição da variação da área ocupada em efeitos escala e substituição e variação no valor bruto da produção (VVBP) na MR Quirinópolis 2000 a 2009

\begin{tabular}{lccccc}
\hline \multicolumn{1}{c}{ Culturas } & EA & EE & ES & EL & VVBP \\
\hline Algodão & -1.585 & -32 & -1.553 & -2.656 .173 & -9.441 .532 \\
Arroz & -2.317 & -67 & -2.251 & -3.076 .240 & -6.098 .525 \\
Cana-de-açúcar & 81.845 & 0 & 81.845 & 5.848 .476 .276 & 267.294 .681 \\
Feijão & -586 & -10 & -576 & -1.247 .535 & -2.796 .371 \\
Milho & -10.247 & -348 & -9.899 & -72.772 .494 & -42.843 .090 \\
Soja & -17.990 & -704 & -17.286 & -91.385 .717 & -69.216 .497 \\
Pastagem & -35.627 & -15.057 & -20.570 & 2.198 & -42.073 .848 \\
Total & 14.157 & -16.273 & 30.430 & - & 93.192 .926 \\
\hline
\end{tabular}

Fonte: Resultados da pesquisa. 
As demais microrregiões que se destacaram pela expansão sucroalcooleira foram respectivamente: MR Sudoeste de Goiás, MR Ceres, MR Rio dos Bois, MR Entorno de Brasília, MR Anápolis e MR Anicuns.

Tabela 11: Decomposição da variação da área ocupada em efeitos escala e substituição e variação no valor bruto da produção (VVBP) na MR Sudoeste de Goiás 2000 a 2009

\begin{tabular}{lccccc}
\hline \multicolumn{1}{c}{ Culturas } & AF-AI & EE & ES & EL & VVBP \\
\hline Algodão & 19.256 & -444 & 19.700 & 115.814 .768 & 76.603 .158 \\
Arroz & -9.385 & -430 & -8.955 & -11.215 .530 & -28.355 .026 \\
Cana-de-açúcar & 54.977 & -678 & 55.655 & -579.3097 .730 & 136.397 .122 \\
Feijão & -6.049 & -418 & -5.630 & -18.202 .564 & -39.158 .466 \\
Milho & 65.341 & -5.825 & 71.165 & 109.430 .567 & -44.583 .406 \\
Soja & 146.892 & -13.615 & 160.507 & -478.784 .093 & -84.577 .441 \\
Pastagem & 209.053 & -33.013 & 242.065 & 344.652 & -52.070 .715 \\
Total & 557.580 & -56.457 & 614.037 & - & -29.722 .428 \\
\hline
\end{tabular}

Fonte: Resultados da pesquisa.

A microrregião Sudoeste de Goiás (Tabela 11) apresentou elevada expansão de área total, com 557 mil ha, indicando acentuado desmatamento no período. Essa expansão se dá, sobretudo, devido às culturas de pastagens, soja, milho, cana-de-açúcar e algodão. Arroz e feijão perdem área embora contribuindo apenas com 14 mil hectares para as culturas em expansão. Apesar da cana-de-açúcar e do algodão terem contribuído positivamente na composição final do valor da produção, a microrregião foi prejudicada pela perda relativa de participação das demais culturas gerando um déficit de R\$ 29 milhões no final do período. O município de Santa Helena se destaca com aumento de 20 mil hectares de área colhida com cana, com uma taxa de $9 \%$ de crescimento da produção explicada principalmente pelo efeito substituição de culturas que perderam área para a cana.

Na microrregião Ceres (Tabela 12), a pastagem sofreu acentuada redução de área (-348.863 ha), alimentando a redução da área total agropecuária (-310.634 ha). Uma vez que uma redução do total de área agropecuária corresponde a um aumento do estoque de terras disponíveis, este resultado sugere aumento de área para os demais usos (urbano, mineração, mananciais hídricos, florestal, culturas permanentes e inaproveitáveis).

A expansão da cana-de-açúcar na microrregião Ceres foi de 52.275 ha e foi a mais distribuída dentre todas, irradiando-se por $60 \%$ dos municípios nesta microrregião. Esse efeito é comprovado pela fonte de variação na taxa anual da quantidade produzida, que em média, apresentou um aumento anual de $70 \%$ ao ano em 10 dos 22 municípios que compõe a microrregião. O município de Goianésia, o mais tradicional representante do setor sucroalcooleiro em Goiás (Abdala e Castro, 2010), teve uma retração de 800 ha na área cultivada com cana-de-açúcar.

Apesar da expansão equilibrada e do valor adicionado pela cultura da cana à composição da produção agropecuária no final do período, a perda de participação das demais culturas gerou um déficit de R\$ 24,4 milhões na composição final na MR Ceres.

Na microrregião Vale do Rio dos Bois (Tabela 13), a expansão da cana-de-açúcar ocorreu em substituição as áreas de algodão e pastagens. Uma perda de 71 mil hectares na área total cultivada sugere aumento de área disponível para outros usos (urbano, mineração, mananciais hídricos, florestal, culturas permanentes e inaproveitáveis). Apesar da contribuição da cana e da soja na composição do valor da produção, a perda de participação relativa de bovinos e algodão contribuem para um déficit de RS 58 milhões no final do período. O município de Edéia se destaca na microrregião, com 13 mil hecta- 
Tabela 12: Decomposição da variação da área ocupada em efeitos escala e substituição e variação no valor bruto da produção (VVBP) na MR Ceres 2000 a 2009

\begin{tabular}{lccccc}
\hline \multicolumn{1}{c}{ Culturas } & AF-AI & EE & ES & EL & VVBP \\
\hline Arroz & -3.749 & -195 & -3.554 & -2.797 .390 & -9.014 .073 \\
Cana-de-açúcar & 52.275 & -497 & 52.773 & -4.633 .955 .342 & 129.551 .194 \\
Feijão & -3.449 & -71 & -3.378 & -3.225 .631 & -10.895 .712 \\
Milho & -11.512 & -552 & -10.960 & -57.578 .831 & -27.452 .056 \\
Soja & 3.821 & -107 & 3.927 & 7.485 .283 & -1.260 .290 \\
Pastagem & -348.863 & -16.289 & -332.574 & -494.261 & -54.281 .905 \\
Total & -310.634 & -17.857 & -292.776 & - & -24.451 .009 \\
\hline
\end{tabular}

Fonte: Resultados da pesquisa.

res de expansão da cana à partir de 2007, explicado pela vantagem comparativa apresentada no efeito localização geografia.

Tabela 13: Decomposição da variação da área ocupada em efeitos escala e substituição e variação no valor bruto da produção (VVBP) na MR Vale do Rio dos Bois 2000 a 2009

\begin{tabular}{lccccc}
\hline \multicolumn{1}{c}{ Culturas } & AF-AI & EE & ES & EL & VVBP \\
\hline Algodão & -36.109 & -720 & -35.389 & -59.160 .314 & -142.311 .588 \\
Arroz & -1.191 & -87 & -1.104 & -500.517 & -1.667 .779 \\
Cana-de-açúcar & 26.518 & -532 & 27.050 & -4.548 .433 .998 & 82.813 .765 \\
Feijão & -1.113 & -54 & -1.058 & -3.142 .009 & -5.855 .879 \\
Milho & 5.875 & -758 & 6.633 & 1.506 .447 & -3.435 .740 \\
Soja & 47.525 & -2.170 & 49.695 & -2.610 .217 & 31.093 .423 \\
Pastagem & -117.258 & -13.529 & -103.730 & -193.008 & -20.131 .192 \\
Total & -71.174 & -18.073 & -53.101 & - & -58.052 .406 \\
\hline
\end{tabular}

Fonte: Resultados da pesquisa.

Na microrregião Entorno de Brasília (Tabela 14) a pastagem cede área à expansão das demais culturas analisadas, as quais apresentam o fator efeito locacional positivo, indicando que a região apresenta vantagens comparativas para todas essas culturas, contudo, a expansão de 46 mil hectares de área agropecuária total sugere a ocorrência de desmatamento na microrregião. Com um aumento de 13,5 mil hectares, Vila Propício é o município de maior destaque na expansão da cultura de cana-de-açúcar, com um aumento de $18 \%$ ao ano explicado principalmente pelo efeito substituição de culturas.

A microrregião Anápolis (Tabela 15), destaca-se pela retração em área de pastagens e na área total, sugerindo aumento de área disponível para outros usos (urbano, mineração, mananciais hídricos, florestal, culturas permanentes e inaproveitáveis). O fator efeito localização geográfica foi negativo para todas as culturas apresentadas indicando expansão abaixo da média do estado de Goiás, entretanto, as culturas de cana-de-açúcar, soja e o rebanho bovino, sustentaram o saldo positivo de R\$ 5,2 milhões verificado na variação da composição de culturas no período. Vale destacar que, apesar da retração da 
Tabela 14: Decomposição da variação da área ocupada em efeitos escala e substituição e variação no valor bruto da produção (VVBP) na MR Entorno de Brasília 2000 a 2009

\begin{tabular}{lccccc}
\hline \multicolumn{1}{c}{ Culturas } & AF-AI & EE & ES & EL & VVBP \\
\hline Algodão & 844 & -117 & 961 & 17.092 .262 & 265.157 \\
Arroz & 1.578 & -134 & 1.712 & 4.733 .486 & -3.735 .898 \\
Cana-de-açúcar & 14.569 & -103 & 14.671 & 125.554 .754 & 24.275 .844 \\
Feijão & 20.294 & -1.019 & 21.314 & 39.379 .781 & -70.574 .263 \\
Milho & 28.666 & -2.237 & 30.902 & 84.977 .249 & -129.445 .219 \\
Soja & 175.904 & -2.688 & 178.592 & 319.519 .791 & 111.751 .948 \\
Pastagem & -231.951 & -29.229 & -202.722 & -126.121 & 45.310 .687 \\
Total & 46.519 & -35.910 & 82.430 & - & 35.246 .105 \\
\hline
\end{tabular}

Fonte: Resultados da pesquisa.

área de pastagens, o valor bruto da produção bovina foi positivo, sugerindo aumento da produtividade das pastagens na microrregião. Itaberaí, Inhumas e Caturaí destacam-se, juntos, com uma expansão de 8 mil hectares na região explicada principalmente pelo efeito substituição.

Tabela 15: Decomposição da variação da área ocupada em efeitos escala e substituição e variação no valor bruto da produção (VVBP) na MR Anápolis 2000 a 2009

\begin{tabular}{lccccc}
\hline \multicolumn{1}{c}{ Culturas } & AF-AI & EE & ES & EL & VVBP \\
\hline Arroz & -3.430 & -210 & -3.220 & -4.700 .835 & -6.154 .468 \\
Cana-de-açúcar & 9.367 & -143 & 9.510 & -1.076 .929 .374 & 26.622 .464 \\
Feijão & -8.961 & -227 & -8.734 & -23.093 .098 & -34.078 .733 \\
Milho & 387 & -671 & 1.058 & -19.075 .067 & -1.475 .966 \\
Soja & 2.606 & -145 & 2.750 & -1.699 .719 & 4.603 .607 \\
Pastagem & -112.612 & -8835 & -103.778 & -164.951 & 5.226 .887 \\
Total & -109.501 & -10.370 & -99.131 & - & 5.486 .590 \\
\hline
\end{tabular}

Fonte: Resultados da pesquisa.

A expansão da cana-de-açúcar é sustentada pela diminuição das demais culturas na microrregião de Anicuns (Tabela 16). A diminuição de 36.321 ha de área total sugere aumento de área disponível para outros usos (urbano, mineração, mananciais hídricos, florestal, culturas permanentes e inaproveitáveis). A vantagem comparativa refletida no efeito localização geográfica ocorre somente para a cultura da soja que, juntamente com a cana-de-açúcar e o rebanho bovino, sustentam um saldo positivo de $R \$ 47,7$ milhões na composição final do valor da produção. A retração de pastagens associada ao saldo positivo do valor bruto da produção de bovinos sugere tecnologia aplicada as mesmas aumentado sua produtividade. Anicuns, Nazário e, a partir de 2005, Turvânia, destacam-se, juntos, com aproximadamente 7 mil hectares, como municípios de maior expansão da cultura. Essa expansão é explicada, sobretudo, pelo efeito substituição de culturas, particularmente a de pastagens. 
Tabela 16: Decomposição da variação da área ocupada em efeitos escala e substituição e variação no valor bruto da produção (VVBP) na MR Anicuns 2000 a 2009

\begin{tabular}{lccccc}
\hline \multicolumn{1}{c}{ Culturas } & AF-AI & EE & ES & EL & VVBP \\
\hline Arroz & -967 & -101 & -866 & -227.865 & -2.313 .544 \\
Cana-de-açúcar & 8.531 & -155 & 8.685 & -1.698 .949 .442 & 18.535 .804 \\
Feijão & -1.514 & -45 & -1.470 & -2.544 .705 & -6.011 .456 \\
Milho & -3.558 & -349 & -3.210 & -27.282 .898 & -6.267 .237 \\
Soja & 1.354 & -21 & 1.375 & 2.507 .636 & 1.415 .581 \\
Pastagem & -40.731 & -6.249 & -34.483 & -86814 & 32.171 .991 \\
Total & -36.321 & -6.946 & -29.375 & - & 47.673 .698 \\
\hline
\end{tabular}

Fonte: Resultados da pesquisa.

As demais regiões do estado de Goiás apresentaram variação marginal na área da cultura de cana-deaçúcar, indicando ser essa variação proveniente da atividade pecuária ou da atividade sucroalcooleira para municípios específicos.

\section{CONCLUSÕES}

Ao longo do período analisado foi possível concluir que a cana-de-açúcar foi a cultura com maior taxa anual de expansão da quantidade produzida.

As culturas temporárias foram as que mais cederam área para as demais culturas que mostraram aumento de área. Assim, culturas tradicionais como milho, algodão, arroz e feijão, entre outras, diminuíram sua participação relativa no total de área cultivada e, mesmo com o superávit gerado pela expansão da cana-de-açúcar, geram um déficit na composição total do valor bruto da produção de culturas temporárias. Tal déficit foi equilibrado pelo aumento do rebanho bovino, que proporcionou saldo final positivo na composição total do conjunto de produtos analisados, confirmando a importância da pecuária na geração de divisas para o estado de Goiás.

Entretanto, para os municípios que apresentaram maior especialização em cana-de-açúcar, as culturas temporárias foram as mais substituídas pela cana. Esse fato sugere que a cana-de-açúcar realmente tem deslocado culturas temporárias, as quais substituem áreas de pastagem em outras localidades, além disso, a categoria área de pastagens foi responsável pela maior variação no saldo final de área agropecuária, indicando ser a maior responsável pela variação de área disponível para outros usos (urbano, mineração, mananciais hídricos, florestal, culturas permanentes e inaproveitáveis), todavia, esta afirmativa carece de maiores investigações.

Sugere-se, portanto, a extensão das análises realizadas neste trabalho para os municípios especializados nessas culturas, bem como o uso de SIG em dinâmica do uso do solo para identificar, georreferenciadamente, as fontes de substituição.

A correlação entre a taxa anual de expansão da cana (EA Cn \%) e o efeito localização geográfica para a cana, indicando a maior expansão da mesma em municípios com maior efeito localização geográfica, permitiu identificar estes municípios e posteriormente investigar os fatores locais que promovem vantagem comparativa aos mesmos, constituindo subsídios às políticas de desenvolvimento local.

Em relação ao uso consuntivo de água, percebe-se que a expansão das lavouras de cana-de-açúcar pode gerar conflitos futuros pelo uso deste recurso, uma vez que esta expansão está ocorrendo em áreas com médio a elevado risco de deficiência hídrica para a irrigação da cultura. 
Das 18 microrregiões analisadas, apenas duas microrregiões, Meia Ponte e Quirinópolis, apresentaram vantagens comparativas para a cana-de-açúcar em relação às demais microrregiões.

Considerando que Meia Ponte é tradicional produtora de cana-de-açúcar e Quirinópolis é recente no cultivo da mesma, pode-se inferir a existência de vantagens comparativas advindas de outras fontes, não necessariamente logísticas, tornando-se necessário aprofundar a análise, para verificação de fatores tais como aptidão edafoclimática para a cultura, além de pesquisas de campo que pretendam evidenciar os fatores de atratividade para a expansão sucroalcooleira no Estado.

Apesar dos impactos decorrentes do processo de especialização dos municípios, a cana-de-açúcar teve valor positivo no valor bruto da produção em todas as regiões onde se verificou sua expansão, contribuindo assim, para agregação de valor na composição agropecuária das mesmas e revelando vantagem econômica competitiva em relação aos demais complexos analisados. Assim, sugerem-se pesquisas, no âmbito de desenvolvimento regional, a fim de identificar como essa vantagem econômica é apropriada pelos municípios em termos de desenvolvimento local sustentável e quais os impactos ambientais dessa vantagem.

A análise da variação da área total cultivada nas microrregiões revelou-se diretamente correlacionada à variação das áreas de pastagens, portanto, sugerindo existência de desmatamento nas microrregiões em que houve aumento da área de pastagens. Para a verificação de tal ocorrência, faz-se necessário um levantamento por meio de pesquisa de campo.

Ao evidenciar a variação do saldo de área agropecuária final, este trabalho identifica municípios para investigação dos motivos relacionados ao desflorestamento sugerido nos resultados, assim, os agentes de fiscalização, tais como o ministério público e a secretaria do meio ambiente dessas localidades deveriam ser alertados.

A utilização conjunta dos indicadores de especialização, do método "shift-share" e das análises de correlação permitiu maior precisão na identificação das fontes de substituição entre as categorias analisadas que o uso individual destas análises, aplicado aos trabalhos aqui referenciados.

\section{BIBLIOGRAFIA}

Abdala, K. O. \& Castro, S. S. (2010). Dinâmica de uso do solo da expansão sucroalcooleira na microrregião meia ponte, Estado de Goiás, Brasil. RBC - Revista Brasileira de Cartografia, 62(4).

Almeida, P. N. A. (2003). Fontes de crescimento e sistema produtivo da orizicultura no Mato Grosso. Dissertação Mestrado em Economia Aplicada, Escola Superior de Agricultura Luiz de Queiroz.

Alves, L. R. A. (2000). Fontes de crescimento das principais culturas no Estado do Paraná (1981 - 1999). Monografia - Graduação em Ciências Econômicas, Universidade Estadual do Oeste do Paraná.

Batalha, M. O. (2001). Gestão agroindustrial 1: Gepai: Grupo de estudo e pesquisas agroindustriais. p. 690, Atlas.

Cardoso, C. E. L. (1995). Efeitos das políticas públicas sobre a produção de mandioca no Brasil. Dissertação - Mestrado em Economia Aplicada, Escola Superior de Agricultura Luiz de Queiroz.

Castro, S. S., Borges, R. O., Silva, R. A. A., \& Barbalho, M. G. S. (2007). Estudo da expansão da canade-açúcar de açúcar no estado de Goiás: Subsídios para uma avaliação do potencial de impactos ambientais. In Impactos econômicos, sociais e ambientais no cultivo da cana-de-açúcar de açúcar no território goiano, pages 09-17. II FORUM DE C \& T NO CERRADO, Goiânia : SBPC.

Curtis, W. (1972). Shift-share analysis as a technique in rural development research. American Journal of Agricultural Economics, 54(2):267-270. 
EMBRAPA-CNPM (2011). Impacto ambiental da Cana-de-Açúcar. Disponível em: http://www.cana.cnpm.embrapa.br/index.html.

Figueiras, G. C. (2002). Crescimento Agrícola no Estado do Pará e a Ação de Políticas Públicas: Avaliação pelo Método shift-share. Dissertação - Mestrado em Economia, Universidade da Amazônia, Belém do Pará.

Haddad, P. R. (1989). Economia regional: Teorias e métodos de análise. Fortaleza, BNB. ETEBE, Economia Regional.

IBGE-PAM (2010). Pesquisa agropecuária municipal. Disponível em: http://www.sidra.ibge.gov.br/bda/acervo/acervo1.asp?e $=\mathrm{p} \& \mathrm{t}=1 \& \mathrm{z}=\mathrm{t} \& \mathrm{o}=3$.

Igreja, A. C. M., Carmo, M. S., Galvão, C. A., \& Pellegrini, R. M. P. (1983). Análise quantitativa do desempenho da agricultura paulista, 1966-77. Agricultura em São Paulo, 30:117-158.

Igreja, A. C. M., de Mello Bliska, F. M., Filgueiras, G. C., Martins, S. S., \& Tirado, G. (2006). Fator locacional na produção brasileira de carne bovina: Uma análise comparada utilizando estatísticas de produção inspecionada versus produção total. Agric., 53(1):63-80.

IPEADATA (2010). Tema: Agropecuária. $\quad$ Nível: Municípios. http://www.ipeadata.gov.br/ipeaweb.dll/ipeadata?SessionID $=705564879 \&$ Tick $=12522$ 8854781\&VAR_FUNCAO=RedirecionaFrameConteudo\%28\%22iframe_dados_r.htm 22\%29\&Mod=R.

Lopes, A. S. (2001). Desenvolvimento Regional. Fundação Calouste Gulbenkian, Lisboa.

MAPA (2010). Relação das Unidades Produtoras Cadastradas no Departamento da Cana-de-açúcar e Agroenergia. http://www.agricultura.gov.br/arq_editor/file/1984_posicao_04_2010.pdf.

Michellon, E., Santos, A. A. L., \& Rodrigues, J. R. A. (2008). Breve descrição do proálcool e perspectivas futuras para o etanol produzido no Brasil. In SOBER, editor, XLVI Congresso Sociedade Brasileira de Economia, Administração e Sociologia Rural. Anais da Sociedade Brasileira de Economia, Administração e Sociologia Rural, Brasília.

Miziara, F. (2009). Expansão da lavoura de cana em Goiás e impactos ambientais. XIV Congresso Brasileiro de Sociologia, 1:1.

Miziara, F. \& Ferreira, N. C. (2008). Expansão da fronteira agrícola e evolução da ocupação e uso do espaço no Estado de Goiás: Subsídios à política ambiental. in:Ferreira, L. G. (org.). In A encruzilhada socioambiental - Biodiversidade, economia e sustentabilidade no cerrado, volume 1, pages 67-75. CEGRAF-UFG.

Moreira, C. G. (1996). Fontes de crescimento das principais culturas do Rio Grande do Norte, 1981-1992. Dissertação (Mestrado) Escola Superior de Agricultura Luiz de Queiroz, Universidade de São Paulo.

MRE (2010). O Estado de Goiás. Disponível em: http://www.mre.gov.br/dc/textos/revista4 mat10.pdf.

Nogueira, M. P. (2009). Os avanços da pecuária de corte. São Paulo: Bigma Consultoria. Disponível em: http://www.bigma.com.br/artigos.asp?id $=49$.

Paranaíba, A. C. \& Pires, M. J. S. (2009). Dinâmica da agropecuária goiana: Um estudo sobre composição agrícola no período 2000 a 2007. Disponível em: http://www.seplan.go.gov.br/sepin/pub/conj/conj10/artigo07.pdf.

Patrick, G. F. (1975). Fontes de crescimento da agricultura brasileira: O setor de culturas. Tecnologia e desenvolvimento agrícola., IPEA/INPES. 
PNA (2006). Plano nacional de agroenergia 2006-2011. Ministério da Agricultura, Pecuária e Abastecimento, Secretaria de Produção e Agroenergia. 2. ed. rev., page 110.

Scheer, M. A. P. S. (2008). Geoprocessamento e o modelo shift-share na análise das transformações do uso da terra em municípios da bacia hidrográfica do Rio Mogi Guaçu (SP), 1979 a 2001. GeoTextos, 4:53-75.

Shikida, P. F. A. \& Alves, L. R. A. A. (2001). Panorama estrutural, dinâmica de crescimento e estratégias tecnológicas da agroindústria canavieira paranaense. Nova Economia, Belo Horizonte,, 11(2):123-149.

Silva, C. R. L. \& Santos, S. A. (2001). Política agrícola e eficiência econômica: O caso da agricultura paulista. PEPGEP, Pontifícia Universidade Católica - SP.

Silva, F. A. M., Müller, A. G., Werneck Lima, J. F., da Silva E., M., F., M., \& Souza Lopes, T. (2008). Avaliação da oferta e da demanda hídrica para o cultivo de cana-de-açúcar no Estado de Goiás. IX Simpósio nacional cerrado., Brasília: Parla Mundi.

Silva, G. L. S. P. d. (1984). Produtividade, pesquisa e extensão rural. São Paulo: IPE/USP.

Souza, P. M. \& Lima, J. E. (2002). Mudanças na composição da produção agrícola no Brasil, 1975 - 1995. Revista Econômica do Nordeste, 33(3).

Tavares, E. C. N., Carvalho, T. B., \& Zen, S. (2009). Rentabilidade econômica da bovinocultura de corte no Estado de Goiás. Anais da Sociedade Brasileira de Economia, XLVII Congresso Sociedade Brasileira de Economia, Administração e Sociologia Rural.

UNICA (2010). Agroindústria da cana-de-açúcar: Alta competitividade canavieira. http://www.unica.com.br/pages/agroindustria_alta.asp.

UNICAMP (2005). Estudo sobre as possibilidades e impactos da produção de grandes quantidades de etanol visando à substituição parcial de gasolina no mundo. Relatório final, UNICAMP.

Vieira Jr., P. A., Vieira, A. C. P., Buainain, A. M., Lima, F., \& Silviera, J. M. F. (2008). Produção brasileira de cana-de-açúcar e deslocamento da fronteira agrícola no Estado do Mato Grosso. Informações Econômicas. Instituto de Economia Agrícola, 38:58-77.

Yokoyama, L. P; Igreja, A. (1992). Principais lavouras da região centro-oeste: Variações no período 19751987. Pesquisa agropecuária brasileira, 27:727-736.

Zockun, M. H. G. P. (1978). A expansão da soja no Brasil: Alguns aspectos da produção. Dissertação (Mestrado), USP/FEA. 